\title{
Social feeding decisions in horses (Equus caballus)
}

Konstanze Krueger, Birgit Flauger

University of Regensburg Department of Biology I

corresponding author: Konstanze Krueger: konstanze-krueger@equine-science.de

'The original publication is available at http://dx.doi.org/10.1016/j.beproc.2008.01.009 May 2008

Behavioural Processes

Volume 78, Issue 1, May 2008, Pages 76-83 doi:10.1016/j.beproc.2008.01.009

\begin{abstract}
Like many other herbivores, in a natural environment equids feed on rather evenly distributed resources. However, the vegetation in their vast habitats constantly changes. If food is plentiful only little competition occurs over food, and in non-competitive situations domestic horses tend to return to the same feeding site until it is overgrazed. In contrast, they compete over limited food for which the social status of the individuals appears to be important. Especially in ruminants several studies have proved an influence of social organisations, rank, sex and the depletion of feeding sites on the feeding behaviour of individuals. However, it is not yet understood whether and how social aspects affect horses' feeding decisions. Curiosity about the influence of social rank on the horses' feeding decisions between two, equally with high-quality surplus food filled buckets placed in different social feeding conditions, led us to create the test below. The observer horses were alternately tested with a dominant and a subordinate demonstrator placed in one of three different positions. We conclude that domestic horses use social cognition and strategic decision making in order to decide where to feed in a social feeding situation. When possible they tend to return to the same, continuously supplied feeding site and switch to an "avoidance tendency" in the presence of dominant horses or when another horse is already feeding there. Thus, the social rank and the position of conspecifics affect the feeding strategy of horses.
\end{abstract}

\section{Keywords:}

Feeding decision; horse; rank; social behaviour.

\section{Introduction}

This study arose from the urgent need to gain more knowledge about the horses' social feeding decisions. In many tests horses discriminate between different food sources, or the horses' learning behaviour is positively reinforced by food rewards. Especially in the case of social learning tasks, in which animals are tested for their ability to learn specific feeding tasks from their conspecifics (see, for instance, Heyes and Galef 1996, Nicol 2006), feeding decisions are influenced by feeding choices of conspecifics. Several studies (Baer et al. 1983, Clarke et al. 1996, Baker and Crawford 1986, Lindberg et al. 1999, Nicol 2002) have been designed to prove social learning in feeding situations in horses. But, even though equids are highly social animals, none of the previous tests were able to demonstrate social learning in horses (Nicol 2002, Krueger and Flauger 2007). Baker and Crawford (1986), as well as Clarke et al. (1996), concluded from the results of their tests that horses learned something, because of the decrease in latency in approaching the test area after observing a demonstrator feeding. However, they may have "avoided" the feeding territory of the unfamiliar demonstrator (i.e. termed "avoidance hypothesis").

Although, the avoidance hypothesis already suggests, that social cognitive abilities, i.e., the processing, encoding, storage, retrieval, and application of social information, is decisive for the outcome of social feeding tests in horses, knowledge on the topic is very limited (Nicol 2002). However, in previous studies we showed that horses are capable of social cognition. They memorise and generalize social experiences (Krueger 2007), and distinguish the social affiliation and the social rank of other horses (Krueger and Heinze accepted).

For a better understanding of the present study we will proceed with outlining the current state of knowledge on social feeding competitions in grazers and 
other mammals, as well as on sociality in equids, and finally draw the main aspects for this study.

In general group life in social animals is determined by complex long-term social relationships (Hinde 1983). The "shareholders" of social interaction may benefit from reduced predation risks, improved defence of resources and communal rearing. On the other hand each of them suffers from increased competition for critical resources to a differential degree (Pusey and Packer 2003).

In grazers, behaviours which are shown while animals compete over more homogeneously distributed and plentiful resources, so called feeding interactions, occur very rarely (Geist 1974, Wittenberger 1981, Wittemyer and Getz 2007, Fischhoff et al. 2007). However, depletion of food sources causes higher competition (Jarman 1974, Illius and Gordon 1987). Analogous, to these findings most competition over food in red deer (Cervus elaphus), Roosevelt elk (Cervus elaphus roosevelti), and caribou (Rangifer tarandus) has been observed in winter when food is scarce (Appleby 1980, Thouless 1990, Weckerly 1999, Barrette and Vandal 1986). Feeding competition in goats (Capra hircus) is influenced by the amount of available food and by the goat's sex, age and rank (Shi and Dunbar 2006). However, feeding conspecifics can also serve as reference point where to find preferred food items (Valone 1989, Valone and Templeton 2002). In this case, the presence of a foraging animal increases the interest of others in a specific feeding area, which has been termed social or local enhancement (Giraldeau 1997, Poysa 1992). It has been shown, that goats (Capra hircus) use social information for locating high quality feeding areas after observing others foraging (Shrader et al. 2007). They also raise their intake rate, in terms of feeding bouts per feeding time, in direct relation to the number of increasing competitors (Shrader et al. 2007). Thus, foraging in groups comprises benefits and costs. Social animals benefit from collective predator protection and social information processing, such as using conspecifics as reference point as described above, but competition over the preferred food items may be costly and even result in serious injuries. Subordinate animals usually pay the highest costs while trying to obtain scarce resources such as food, water, rest places and shelter in the presence of dominant animals (Barton 1993a and 1993b). In chimpanzees (Hare et al. 2000), for instance, subordinate animals only choose food that is hidden behind a small barrier in such a way that the dominant animal can not see it. Hare et al. (2001) even highlighted that chimpanzees seem to know which particular animal has watched the crucial event, since subordinates go for food when the observing dominant animal is exchanged for a non-observing dominant animal.

However, it is not yet understood whether and how social aspects affect horses' feeding decisions.
Equids live in fission-fusion social systems (Fischhoff et al. 2007) in which the members of social groups frequently disperse and reunite again. Though, social live takes different shapes in equids, for species, which live in wide grasslands, such as the Serengeti Plain of Tanzania (Moehlman 2002), the valleys of Hustai National Park in Mongolia (King and Gurnell 2005) and the "Great Basin" in northern America (Berger 1986), food and water resources are sufficient enough to allow females to feed together and to thus form stable groups, which consist of one or more mares, their offspring and usually one, but occasionally up to five males (i.e. referred to as "harem" or "family, Tyler 1972, Berger 1977, Moehlman 2002). Surplus stallions gather in separate bachelor bands that differ in size from 2 to approximately 17 horses (Berger 1977). Many subgroups form a structured social unit, called "herd," which shows the same migration patterns within a common home range (Miller 1979, Berger 1986). Horses roam in vast habitats and spend an average of $60 \%$ of their time feeding on constantly changing vegetation (Salter and Hudson 1979, Waring 2003). They prefer to feed on grasses in areas where preferred food is more plentiful (Duncan 1983, Salter and Hudson 1979). In non competitive situations, while horses feed all by themselves with no other horses near by, domestic horses tended to return to the same feeding site until it is overgrazed (Devenport et al. 2005).

When food sources are limited the social status of the individuals appears to be important. In the context of determining dominance relationships among domestic horses, paired feeding tests, an interaction contest over the limited resource "food", have often been applied (Houpt et al. 1978, Ellard and Crowell-Davis 1989). This technique is still in use for several species, like monkeys and apes, today ( $\mathrm{Li}$ et al. 2007), although doubts arose concerning the reliability of dominance hierarchies investigated in the contest over point resources for species, that generally feed on rather homogeneously distributed resources. Ellard and Crowell-Davis (1989) were the first to mention that the results of such a test with draft-horse mares did not match their observations of the dominance hierarchy of the same horses in the field. Accordingly, in recent studies (Heitor et al. 2006a and 2006b, Ellard and Crowell-Davis 1989, Linklater and Cameron 2000, Berger 1977, Houpt et al. 1978, Houpt and Wolski 1980, Goldschmidt-Rothschild and Tschanz 1978), dominance relationships in horses have been assessed by using approach-retreat interaction and the direction of threats and submissive gestures (McDonnell 2003, McDonnell and Haviland 1995, Feist and McCullough 1976).

Curiosity about the influence of social rank on the horses' feeding decisions between two, equally with high-quality surplus food filled buckets placed in different social feeding conditions, led us to create the 
test below. Both feed-buckets were black in colour and marked with olfactory cues from prior feeding of the test horses. The observer horses were alternately tested with a dominant and a subordinate demonstrator, which were determined from dominance relationship data observed in the field. The demonstrator was placed in one of three different positions either defined as i) demonstrator feeding, ii) demonstrator tied up or iii) demonstrator absent. We hypothesised that the decisions of the observer horses would be strongly influenced by the demonstrators ' rank in all three feeding situations.

\section{Materials and Methods}

\section{Animals}

We investigated the behaviour of 14 horses: 11 standard bred horses and 3 ponies (composed of 12 mares and 2 geldings), all aged between 6 and 30 years. The horses were individually identified by their brands and coloration. For testing social behaviours the social background and the housing conditions of the animals are of importance. Socially kept animals might behave differently from those that are kept individually. The horses that took part in the tests were members of three social groups with 6,6 and 4 horses, respectively (table 1). Two horses in group 1 and 2 are genetically related (mother-daughter relationships in both cases). The composition of group 1 has been stable for 6 years. Group 3 was established one year ago, but the members of the group had contact to each other for several years. In group 2, four horses represent the core of this group and have been together for six years; they were joined by two new horses only three months ago. Because of their short time in the group, those two horses were not used in the feeding tests. Nevertheless, to maintain a complete dominance hierarchy, their dominance data has been retained in the dominance tables but is labelled with an asterisk.

The three groups were kept in different types of stables. Horses of groups 1 and 3 were kept in social groups in open stabling, with a bedding of straw, in group 1, and wood shavings, in group 3 . They received daily access to their pastures. The horses in group 2 were housed in individual box stalls (sized: $3 \mathrm{~m} \times 4 \mathrm{~m}$, with a bedding of straw) overnight and turned out in a social group in a paddock during the day. The daily feed of the horses was composed of hay twice a day and a compound feed once a day, in groups 1 and 3 . Whereas group 2 received hay and a compound feed twice a day. In addition they all had access to grazing while turned out.

Dominance relationships

Before starting the experiments, we determined the dominance relationships among the horses in the field by observing agonistic encounters, such as approaches, retreats, threats to bite or kick, bites, kicks and chases (McDonnell2003, Mc Donnell and Haviland1995, Feist and McCullough1976). For specific sampling of the dominance interaction described above, horses were observed over 6 hours on separate days (at least three different days, with a minimum duration of $30 \mathrm{~min}$. and a maximum of $150 \mathrm{~min}$. each). Observations had to be adjusted to accommodate the horses ' commitments as riding horses, but were distributed over daylight period. The interactions of the horses were recorded continuously. For the calculation of the individual dominance scores, we added instances of active antagonism and subtracted cases of retreat (Table 1).

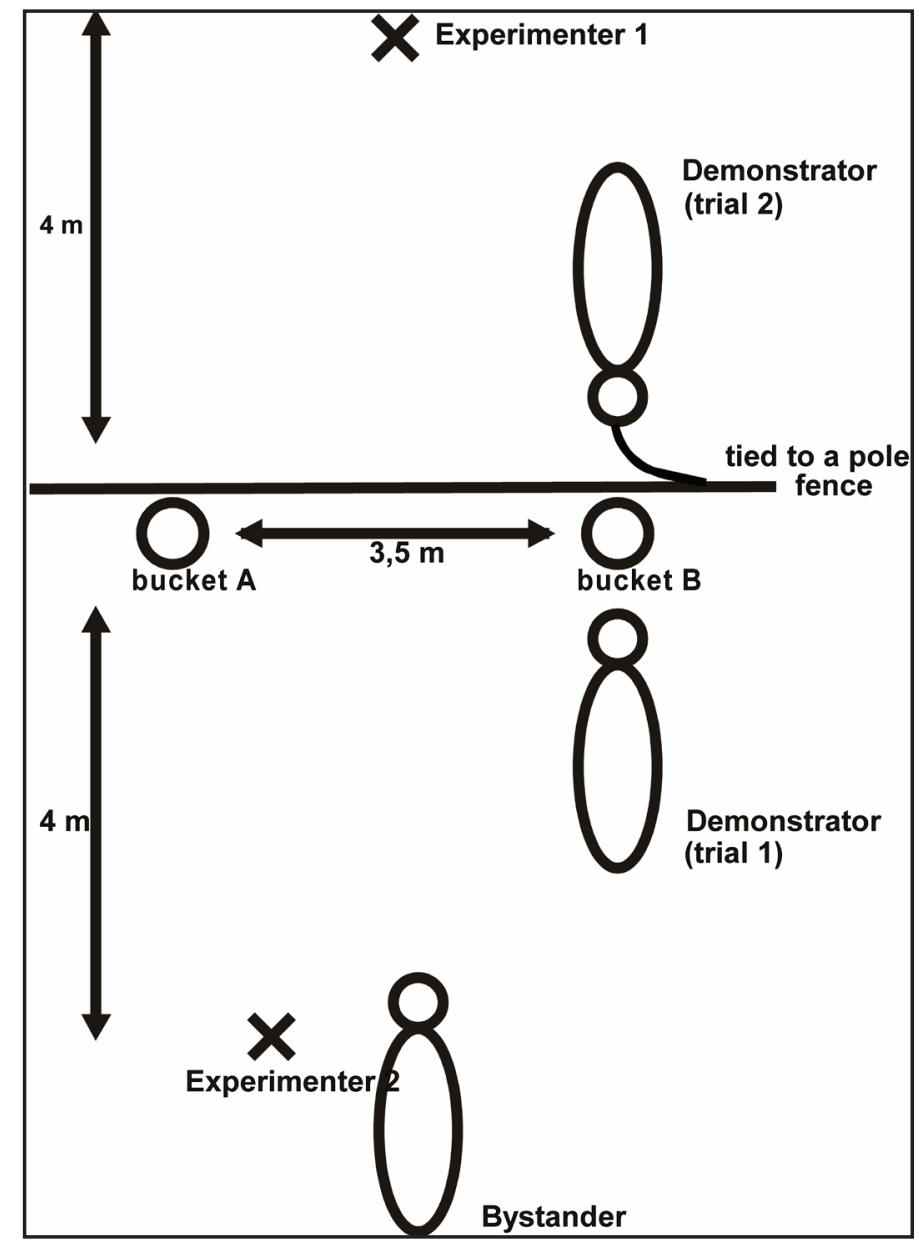

Figure 1 - Experimental set-up feeding test

Buckets A and B always contained food. Trial 1, 4, 9 and 12: Demonstrator horse continuously feeds from a specific bucket. Trial 2, 5, 8 and 11: Demonstrator horse, tied up to a post beside the bucket it had previously been feeding from for 5 seconds. Trial 3 , 6, 7 and 10: Demonstrator horse was led out of the observer horse's sight after feeding from a specific bucket for 5 seconds. 


\begin{tabular}{|c|c|c|c|c|c|}
\hline group1 & age & sex & breeds & related & dom. score \\
\hline Billy & 18 & gelding & Warm-blood & no & 47 \\
\hline Sara & 22 & mare & Haflinger & no & 38 \\
\hline Farina & 23 & mare & Warm-blood & no & 18 \\
\hline Peppermint & 14 & gelding & Pony & no & 4 \\
\hline Anouschka & 6 & mare & Haflinger & daughter & -14 \\
\hline Alexia & 20 & mare & Haflinger & mother & -28 \\
\hline group2 & age & sex & breeds & related & dom. score \\
\hline Monty* & 9 & gelding & Paint-horse & no & 83 \\
\hline Manon & 21 & mare & Warm-blood & mother & 77 \\
\hline Mahranya & 7 & mare & Warm-blood & daughter & 69 \\
\hline Lady & 16 & mare & Appaloosa & no & 3 \\
\hline Daisy & 30 & mare & Warm-blood & no & -29 \\
\hline Grandessa* & 17 & mare & Warm-blood & no & -48 \\
\hline \multicolumn{6}{|c|}{${ }^{*}$ horses which joined the group only three month ago } \\
\hline aroun 3 & 390 & $\cos$ & hroeds & related & dom scoro \\
\hline Francis & 13 & mare & Warm-blood & no & 34 \\
\hline Traum & 14 & mare & Warm-blood & no & 8 \\
\hline Miss Lala & 27 & mare & Pony & no & 2 \\
\hline La Belle & 14 & mare & Pony & no & -30 \\
\hline
\end{tabular}

Table 1: Dominance hierarchy of horses

Experimental set-up feeding test

The experimental area $(8 \mathrm{~m} \times 8 \mathrm{~m}$, separated by fencing, Fig. 1) for groups 1 and 3 was a part of their open stable, and for group 2 it was a part of their riding arena. Two food-buckets (black, $35 \mathrm{~cm}$ diameter) were placed in the feeding area at a distance of 3.5 meters apart. To prevent poor performance caused by reinforcer satiation on a single food item (Miyashita et al.2000) the buckets were constantly filled with three different food items, such as a mixture of compound feed, carrots and apples for groups 1 and 3. Because one horse of group 2 previously showed signs of colic after feeding on apples, horses of this group received the first two food items and bread instead of apples. In addition, large stones were added to the feed buckets to prevent the horses from eating too fast and getting too much feed of high nutritional value. The area opposite the feeding region served as an observation area for an observer horse. The fences next to the buckets could be opened to remove the demonstrator horse.

\section{Experimenter}

Three people took part in the study as experimenters: person 1 in the trials of group 1 and 3 , person 2 in the trials of all three groups and person 3 only in the trials of group 2. Experimenter 1 handled the demonstrator horses and refilled the food buckets. Experimenter 2 handled the observer horses. In all cases experimenter 1 was unfamiliar to the horses.

Experimental procedure feeding test

Before starting the experiments, all the horses were habituated to the experimental set-up (fig. 1). All horses were fed from both buckets, and the buckets were continuously refilled to show the horses that there will always be food in both buckets. The experiments were conducted between 9 a.m. and 1 p.m. The normal first feeding time for all groups was at 7 a.m.

For trials 1-6 the respective horses of a group were tested on one test day in the following order: demonstrator feeding, demonstrator tied-up and demonstrator absent. To prevent a serial-order-effect on the rank of the demonstrator horses we conducted each feeding situation with a subordinate and a dominant demonstrator in random order. Two weeks later, the horses of groups 1 and 3 were tested in 6 additional trials in the same manner but in reversed order (trials 7-12, table 2, fig. 2 and 3). Unfortunately, the horses of group 2 could not be used for this study any more, because the subordinate demonstrator of this group developed permanent teeth problems, which affect its feeding behaviour. Finally, two month later, horses of group 1 and 3 were tested in control trials (trials 13-15, table 2, fig. 3 ) similar to trials $4-6$, because we did not test them in the original trial 6 . For 
the original trial 6 , we acted on the assumption that those horses would retain their tendency from trial 5 to return to the same bucket.

Trial 1, 4, 7, 10 and 13: Demonstrator feeding:

The demonstrator horse was led to a specific bucket in the feeding area by experimenter 1 , and released from a lead rope. It immediately ate from the bucket. Experimenter 1 moved 4 meters away and turned her back to the eating demonstrator. The observer horse watched the demonstrator horse eating for 5 seconds and then was released from a leadrope to choose a feed bucket in the feeding area. Experimenter 2, as well, moved 1 additional meter away from the horses and turned her back to them.

Trial 2, 5, 8, 11 and 14: Demonstrator tied up:

The experimental procedure was similar to the trials "demonstrator feeding" with the exception that the demonstrator horse, after it was allowed to eat for 5 seconds from a specific bucket, was tied up to a post and separated from the bucket it had just fed from by a fence. The observer was released when the demonstrator was already tied up.

Trial 3, 6, 9, 12 and 15: Demonstrator absent:

Again, the experimental procedure was similar to the trials "demonstrator feeding", but after eating from the bucket the demonstrator horse was caught by experimenter 1, and led out of sight of the observer horse (i.e. out of the experimental area). Only then was the observer horse released into the feeding area.

Trials $7-12$ : trials in reversed order

We conducted an identical experimental procedure as the trials 1-6, but in reversed order, starting with the demonstrator absent (trials 9 and 12), followed by the demonstrator tied up (trials 8 and 11) and the demonstrator already feeding (trials 7 and 10).

Trials 13-15: control for the missing trial 6 in group 1 and 3.
We tested for the missing trial 6 in group 1 and 3 in terms of creating a test day similar to the one for the original trials 4-6, and therefore, tested horses of group 1 and 3 in all three trials with a subordinate demonstrator a second time in the original order.

In order to standardize the testing for all horses, the order in which the demonstrator horse fed from the buckets in the presence of each observer horse in each trial was as follows: bucket $B, A, B, B, A, A$. Bucket $A$ was always positioned to the left side and bucket $B$ to the right side of the observers start position (fig. 1). By leading the demonstrator alternately, but not regularly, to the left and to the right side we tried to prevent a lateralisation bias in the observer horse.

Statistics and visualisations

Analysis was done with the R statistical environment (2007) and the statistical software SPSS. We applied Generalized Estimating Equations (GEEs), for binomial data, to solve a complex likelihood equation for the influence of the demonstrator position, its rank, and the rank of the observer on the observer horses bucket choice in contrast to the demonstrators' bucket-choice. But for the respective feeding situations we investigated the significance for the probability of the observers to choose the same bucket as the demonstrator. Therefore additional GEEs tested the probability of the observer horses bucket choice ("bucket observer") to be analogous to the response variable ("bucket demonstrator") with the demonstrators rank as an additional explanatory variable Finally we applied a Chi-Square Test (SPSS) for evidence of the horses 'tendency to return to a specific feedbucket. Tables and Figures were visualised with the R statistical environment (2007).

\begin{tabular}{|l|l|l|l|}
\hline Trial number & demonstrator rank & feeding situation & trial type \\
\hline 1 & dominant & demonstrator feeding & original \\
\hline 2 & dominant & demonstrator tied & original \\
\hline 3 & dominant & demonstrator absent & original \\
\hline 4 & subordinate & demonstrator feeding & original \\
\hline 5 & subordinate & demonstrator tied & original \\
\hline 6 & subordinate & demonstrator absent & original \\
\hline 12 & subordinate & demonstrator absent & reverse \\
\hline 11 & subordinate & demonstrator tied & reverse \\
\hline 10 & subordinate & demonstrator feeding & reverse \\
\hline 9 & dominant & demonstrator absent & reverse \\
\hline 8 & dominant & demonstrator tied & reverse \\
\hline 7 & dominant & demonstrator feeding & control \\
\hline 13 & subordinate & demonstrator feeding & control \\
\hline 14 & subordinate & demonstrator tied & control \\
\hline 15 & subordinate & demonstrator absent & control \\
\hline
\end{tabular}

Table 2: Trials 


\section{Results}

Feeding test

We analysed the general influence of the demonstrators' position, their rank and the rank of the observer on the probability of the observer horses bucket-choices for the original trials 1-6 and the reversed trials 7-12 (table 3 ). The control trials for the situations in which a subordinate demonstrator fed were analysed for an influence of the demonstrators' position and the rank of the observer (table 3). Figure 2 illustrates the observers' bucket choice when confronted with a dominant demonstrator in each of the three possible positions (trial 1-3: original and trials 7-9: reverse), and figure 3 with a subordinate demonstrator in the same three positions (trials 4-6: original, trials 10-12 reverse and trials $13-15$ control). The position of the demonstrator (feeding, tied up or absent) significantly influences the observers bucket choices in the trials 1-6, in the reversed trials $7-12$, and the subordinate control trials (all $p<0.001$, table $3)$. The same is true for the rank of the demonstrator in the trial 1-6 ( $p=0.018$, table 3$)$. However, for the reversed trials 7-12 no significance in the rank of the demonstrator was observed ( $p=0.875$, table 3 ). The rank of the observer horses was not significant in any of the cases examined (all $p>0.05$, table 3 ).

For a closer analysis of the observers bucket choice compared to the demonstrator in the respective feeding conditions we conducted separate GEEs. Be-

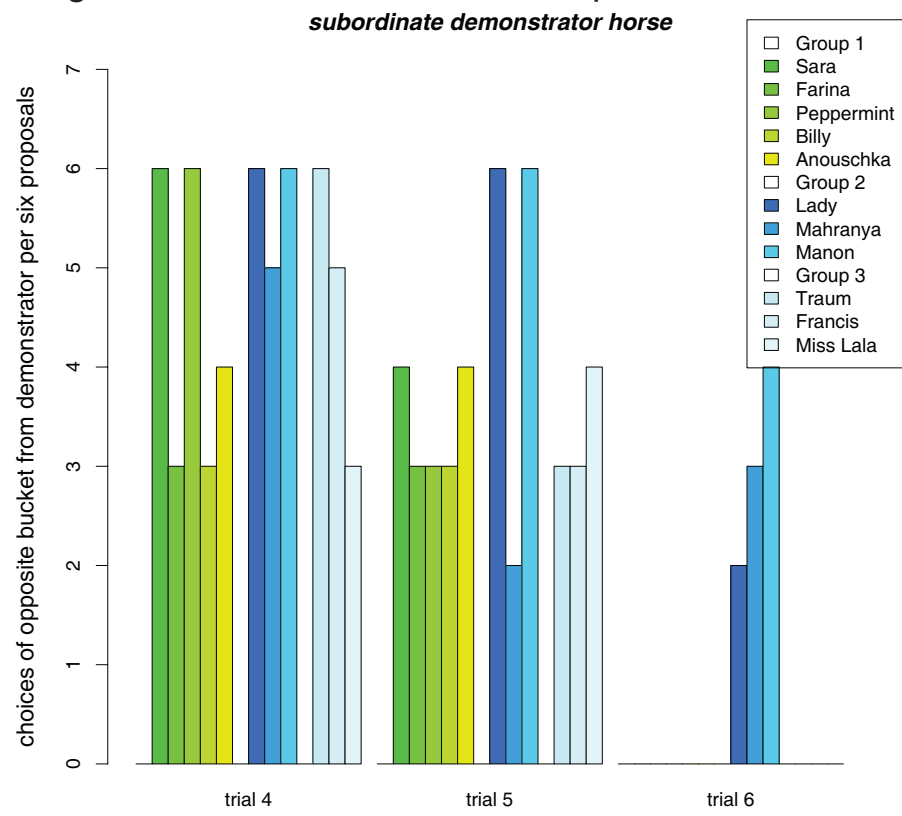

Figure 2 - Feeding test, dominant demonstrator

The observers' bucket choices contrary to those of a dominant demonstrator significantly differ in the respective feeding situations, such as demonstrator continuously feeding (trial 1 and 7 ), or tied up (trial 2 and 8 ) or absent (trial 3 and 9), because the position of the latter significantly influences the observers bucket choices in the original trials 1-3 and in the reversed trials $7-9$ (all $p<0.001$, table 3 ). cause the observers rank did not have any significant influence on the probability of choosing a specific bucket throughout the test, we excluded "observer rank" from the following formulas but kept demonstrator rank, which proved to be significant in the trials 1 6 . When the demonstrator was eating, the observer horses generally tended to choose the other bucket (all $p<0.001$, table 3). Even though the statistical data for trial 2 and 5 show significance for the observers' choice of the bucket that had not been used by the demonstrator when the demonstrator was tied up (position 2) ( $p<0.001$, table 3$)$, the visualised data (fig. 2 and 3 ) illustrate that this choice was not as consistent as in the trials 1 and 4 . In fact, in the analogous but reversed trials 8 and $11(p=0.182$, table 3 ) and the control trial $14(p=0.328$, table 3$)$ the choice was not statistically significant. The third position, with the demonstrator absent, also failed to show any significant choice for the other bucket the demonstrator previously ate from (all $p>0.05$, table 3 ). The demonstrators rank appeared to be of minor importance in the respective feeding situations ( $p$ of all tests $>0.05$ )

In general, horses that did not choose the buckets opposite from those from which the demonstrator had previously fed showed a strong tendency to return to the same bucket, i.e. either bucket $A$ or $B$, in the trials 1-6 (Chi-Square-Test: $N=192, X^{2}=90.750$, $\mathrm{df}=1, p<0,001)$ and in the trials of reversed order (7-12) (Chi-Square-Test: $N=132, X^{2}=39.273$, df $=1$, $p<0,001)$. Deviations of only one choice were considered to be due to chance.

Finally, it appeared to be noteworthy that Lady, a member of group 2, received an aggressive action from the dominant demonstrator in trial 1 while trying to feed from the same bucket. In trial 2 and 3 she avoided the buckets from which the same dominant demonstrator had previously fed (Fig. 2).

\section{Discussion}

In the present study observer horses were tested for their choice among two food buckets from which a demonstrator horse fed in three respective feeding situations, such as i) demonstrator constantly feeding, ii) demonstrator tied up beside a specific food bucket or iii) demonstrator absent after feeding from a specific food bucket. In each of these social feeding situations the observer horse could decide a) to stay with the tendency of returning to a specific feeding area, or b) to use the feeding conspecific as reference point for the best food source, or finally $c$ ) to avoid the feeding territory of its conspecific.

Observer horses obviously avoid feeding from the demonstrators' bucket in direct confrontation, i.e. while the demonstrator is eating. However, for the feeding conditions in which the demonstrator was 


\begin{tabular}{|c|c|c|c|c|c|c|c|}
\hline $\begin{array}{l}\text { Generalized Es } \\
\text { Formula: (chc } \\
\text { corstr="exchan }\end{array}$ & $\begin{array}{l}\text { timating Equations (GE } \\
\text { ice position.dem + } \\
\text { yeable“) }\end{array}$ & rank.d & + & observ & & far & \\
\hline \multicolumn{4}{|c|}{ impact on choice $(\mathrm{N}=348)$} & \multicolumn{2}{|c|}{ reverse trials $(\mathrm{N}=288)$} & \multicolumn{2}{|c|}{$\begin{array}{l}\text { control trial }(N= \\
144)\end{array}$} \\
\hline response & predictors & robust z & $p$ - value & robust z & $p$ - value & robust z & $p$ - value \\
\hline \multirow[t]{3}{*}{ choice observ. } & position demonstrator & $-5,472$ & $<0,001$ & $-7,175$ & $<0,001$ & -5.975 & $<0,001$ \\
\hline & rank demonstrator & $-2,372$ & 0,018 & 0,157 & 0,875 & & \\
\hline & rank observer & $-2,551$ & 0,980 & 0,048 & 0,962 & -0.662 & 0.508 \\
\hline \multicolumn{8}{|c|}{ Formula:(bucket.dem bucket.observ+rank.dem, id=nr.observer, family="binomial", corstr="independence") } \\
\hline \multicolumn{4}{|c|}{ Demonstrator feeding $(\mathrm{N}=132)$} & \multicolumn{2}{|c|}{ reverse trials $(\mathrm{N}=96)$} & \multicolumn{2}{|c|}{ control trial $(\mathrm{N}=48)$} \\
\hline response & predictors & robust z & $p$ - value & robust z & $p$ - value & robust z & $p$ - value \\
\hline \multirow[t]{2}{*}{ bucket dem. } & bucket observer & $-3,934$ & $<0,001$ & $-1,334$ & 0,182 & -0.978 & 0.328 \\
\hline & rank demonstrator & 0,581 & 0,561 & $-0,479$ & 0,632 & & \\
\hline \multicolumn{4}{|c|}{ Demonstrator tied $(\mathrm{N}=132)$} & \multicolumn{2}{|c|}{ reverse trials $(\mathrm{N}=96)$} & \multicolumn{2}{|c|}{ control trial $(\mathrm{N}=48)$} \\
\hline response & predictors & robust $z$ & $p$ - value & robust z & $p$ - value & robust $z$ & $p$ - value \\
\hline \multirow[t]{2}{*}{ bucket dem. } & bucket observer & $-3,934$ & $<0,001$ & $-1,334$ & 0,182 & -0.978 & 0.328 \\
\hline & rank demonstrator & 0,581 & 0,561 & $-0,479$ & 0,632 & & \\
\hline \multicolumn{4}{|c|}{ Demonstrator absent $(\mathrm{N}=84)$} & \multicolumn{2}{|c|}{ reverse trials $(\mathrm{N}=96)$} & \multicolumn{2}{|c|}{ control trial $(\mathrm{N}=48)$} \\
\hline response & predictors & robust z & $p$ - value & robust z & $p$ - value & robust z & $p$ - value \\
\hline \multirow[t]{2}{*}{ bucket dem. } & bucket observer & $-0,499$ & 0,618 & $-1,572$ & 0,116 & 1.088 & 0.277 \\
\hline & rank demonstrator & 0,468 & 0,640 & $-0,487$ & 0,626 & & \\
\hline
\end{tabular}

Table 3: Results

tied up beside a bucket horses started to develop a strong tendency to return to the same feeding site they chose before, and displayed this tendency, even stronger, when a demonstrator was absent after feeding, similar to what has been reported by Devenport et al. (2005) for non-competitive situations.

Furthermore, the demonstrators ' rank did have a significant effect on the observer horses feeding decisions for the original test (trials 1-6). Nevertheless, the effect was weaker as we expected it to be. It appeared to be strongest for the situation in which the demonstrator was tied beside a bucket, which means that observer horses avoided feeding from a bucket with a dominant demonstrator but not with a subordinate demonstrator tied beside it.

However for the repetitions of the test, during the reversed and the control trials, the influence of the demonstrators rank diminished. On the one hand, observer horses might simply learn that demonstrator horses will not challenge their feeding decisions in the trials when the latter are tied or absent, no matter what the demonstrators' rank might be. On the other hand, the declining influence of the demonstrators rank could be due to the fact, that observer horses are repeatedly, positively reinforced from equally filled food-buckets and they simply avoid unnecessary costs for feeding competitions even with subordinate animals. One could also argue, that, prior to the test, domestic horses had learned in their daily routines, or in more natural feeding situations (Duncan 1983, Salter and Hudson 1979), that they have to compete for high-quality-food, but, during the repetitions of the test, experience that the preferred food will be available ad libitum. The best option to control for these effects in an additional test series would probably emerge from testing the respective feeding situations in random order, such as mixing trials with the demonstrator feeding, tied or absent, as well as the subordinate and dominant demonstrator horses. Another option, of testing horses with only one food source from which the demonstrator feeds, would result in frustration and thus demotivation of the observer horse, and, in addition, would not allow testing for alternative feeding decisions.

Also in social learning tasks observer horses have been tested for feeding decision over equally supplied food sources (Baer et al. 1983, Clarke et al. 1996, Baker and Crawford 1986, Lindberg et al. 1999), when the demonstrator horse was already out of sight. From the outcome of our tests we conclude that, in this feeding situation, the rank of the demonstrator horse would not affect the choice of the observer horses. Furthermore, we suggest, that the "avoidance hypothesis", which has been proposed in order to explain the feeding choices of observer horses in social learning tasks (Baker and Crawford 1986, Clarke et al. 1996), can not be supported any longer. In our study we could not find an avoidance 


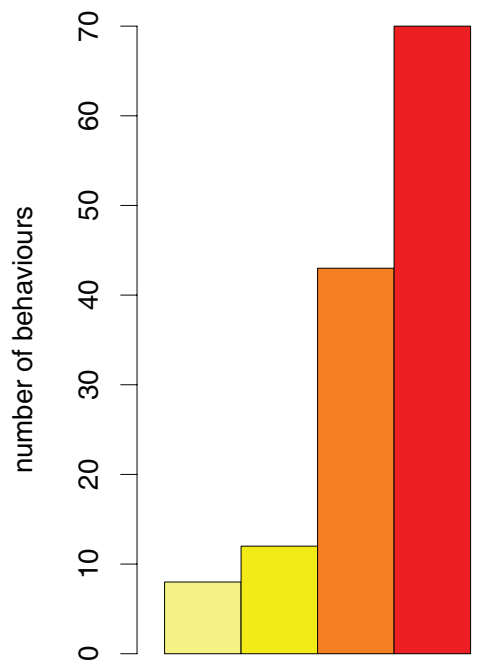

agonistic encounters

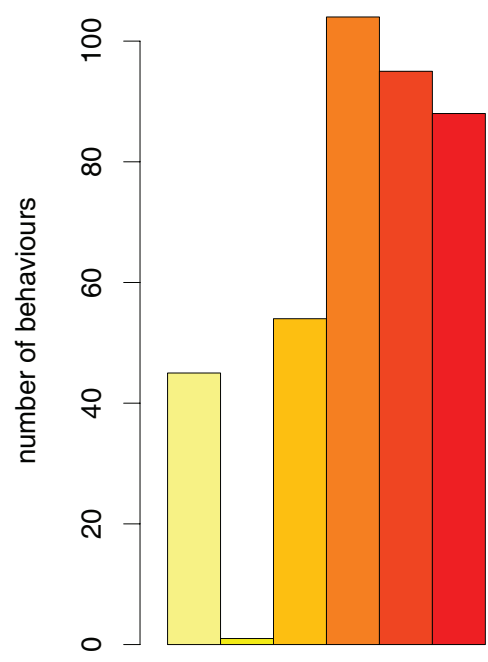

agonistic encounters

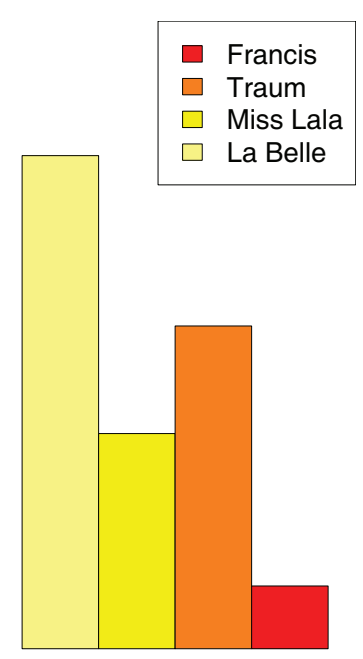

retreats, followings

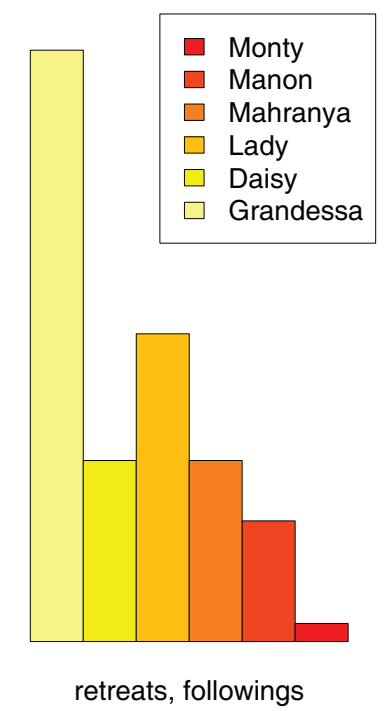

tendency for the bucket the demonstrator horse fed from when the latter was absent. Rather a tendency to return to the same feeding site might have biased the social learning tests. Horses appear to stay with this tendency no matter what the demonstrator horses' rank is and whether they are confronted with evenly distributed low-quality food (Devenport et al. 2005) or with limited high quality food. Their motivation to adopt a different feeding strategy from their natural feeding habit might be low in situations where unlimited food rewards are given or food rewards can not be controlled by the dominant animal (Laland 2004)

Consequently, we agree with Clarke et al. (1996) that the learning effect due to local enhancement, which has been reported to cause a faster approach to the feeding area in the learning situation than in the control trials, is connected to the general feeding location and not to a specific bucket. Furthermore horses did not use social information after observing conspecifics feeding, in terms of using their conspecifics as reference points for where to feed (i.e. through social

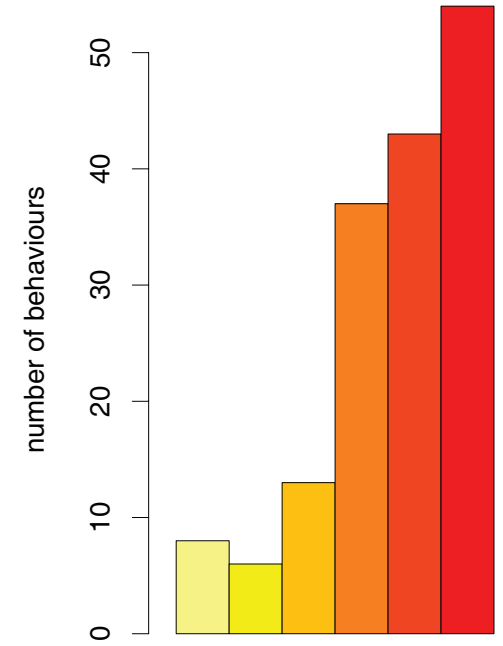

agonistic encounters

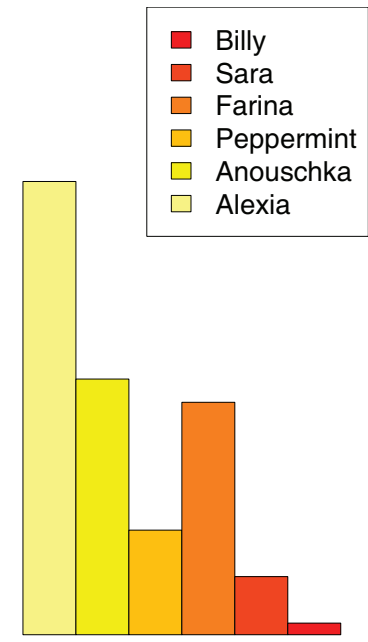

retreats, followings
Figure 3 - Feeding test, subordinate demonstrator The observers 'bucket choices contrary to those of a subordinate demonstrator significantly differ while the latter was either continuously feeding (trial 4, 10 and 13), or tied up (trial 5, 11 and 14) or absent (trial 6,12 and 15), because the position of the demonstrator similarly influences the observers bucket choices in the original trials 4-6, in the reversed trials 10-12, and the subordinate control trials 13-15 (all $p<0.001$, table 3).

enhancement, Giraldeau 1997, Poysa 1992) or to select a feeding area of higher food-quality (Shrader et al. 2007). Rather than feeding from the same bucket as the demonstrator horses, the observer horses preferred to return to always the same feeding site. This situation might be enhanced by a habituation of the test horses to constantly filled buckets prior to the tests. Horses might not have feared that there is no food left in the buckets, which has been hypothesised by Baker and Crawford (1986).

Furthermore, the fact that horses change their feeding strategies, depending on whether food is limited or plentiful, might explain the contradictory results of dominance evaluations on feeding competition tests over a limited food source to those evaluated from behaviour observations in the field (Ellard and Crowell-Davis 1989, Houpt et al. 1978, Heitor et al 2006a and 2006b). In addition, for behavioural observations in the field, competition for all resources is decisive for the construction of dominance hierarchies. Food represents only one of the valued resources, and individuals might cherish resources to a differential degree (Pusey and Packer 2003).

Finally, we would like to stress the point that the more general lack of avoidance is not due to a cognitive inability to remember where the demonstrator last fed, but rather to a social strategic decision-making process. In some cases, previous feeding experiences affect the observers' feeding choice, such as in Lady's case, where, after receiving an aggressive action from the dominant demonstrator in trial 1, she did not dare to feed from the same bucket either in 
the demonstrator's presence or in its absence. Lady, as well as other horses, who avoided feeding from the same buckets as the demonstrators even in their absence, showed an excellent memory for the demonstrators ' choices.

Conclusion

In a nutshell, domestic horses use social cognition and strategic decision making in order to decide where to feed in a social feeding situation. Whenever possible they tend to return to the same, continuously supplied feeding site and switch to an "avoidance tendency" in the presence of dominant horses, or when another horse is already eating there. Thus, the social rank and the position of conspecifics affect the feeding strategy of horses.

\section{Acknowledgements}

We wish to thank Katherine Albro Houpt for discussions about horses' dominance relationships, Christine Nicol for discussing the scientific background, Juergen Heinze for helpful suggestions, Elisabeth D'Antoni and Jon Seal for language corrections, Knut Krüger for the analysis in " $\mathrm{R}$ statistical environment" and all the owners of the horses who allowed us to test their horses or even helped with the tests. We also thank two anonymous referees for all their effort they put into improving an earlier draft of the manuscript. The study was supported by an HWP II grant of the University of Regensburg and an Excellence grant of the Bavarian Government.

\section{References}

Appleby, M.C., 1980. Social rank and food access in red deer stags. Behavior, 74, 294-309.

Baer, K.L., Potter, G.D., Friend, T.H. and Beaver, B.V., 1983. Observation effects on learning in horses. Appl. Animal. Ethol., 11, 123-129.

Baker, A.E.M. and Crawford, B.H., 1986. Observational learning in horses. Appl. Anim. Behav. Sci., 15, 7-13.

Barette, C. and Vandal, D., 1986. Social rank, dominance, antler size, and access to food in snow-bound wild woodland caribou. Behaviour, 97, 118-146.

Barton, R.A., 1993. Sociospatial mechanisms of feeding competition in female olive baboons, Papio anubis. Animal Behaviour, 46, 791-802.

Barton, R.A. and Whiten, A., 1993. Feeding competition among female olive baboons, Papio anubis. Animal Behaviour, 46, 777-789.

Berger, J., 1977. Organizational systems and dominance in feral horses in the Grand Canyon. Behav. Ecol. Sociobiol., 2, 131-146.

Berger, J., 1986. Wild Horses of the Great Basin: Social Competition and Population Size. University of Chicago Press, Chicago.

Brennan, J. and Anderson, J., 1988. Varying respon- ses to feeding competition in a group of rhesus monkeys (Macaca mulatta). Primates, 29, 353-360.

Clarke, J.V., Nicol, C.J., Jones, R. and McGreevy, P.D., 1996. Effects of observational learning on food selection in horses. Appl. Anim. Behav. Sci., 50, 177184.

Deutsch, J. and Lee, P., 1991. Dominance and feeding competition in captive rhesus monkeys. Int. J. Primatol., 12, 615-628.

Devenport, J.A., Patterson, M.R. and Devenport, L.D., 2005. Dynamic averaging and foraging decisions in horses (Equus callabus). J Comp Psychol, 119, 352-358.

Dubuc, C. and Chapais, B., 2007. Feeding Competition in Macaca fascicularis : An Assessment of the Early Arrival Tactic. International Journal of Primatology, 28, 357-367.

Duncan, P., 1983. Determinants of the use of habitat by horses in a mediterranean wetland. J. Anim. Ecol., 52, 93-109.

Ellard, M.-E. and Crowell-Davis, S.L., 1989. Evaluating equine dominance in draft mares. Appl. Anim. Behav. Sci., 24, 55-75.

Feist, J.D. and McCullough, D.R., 1976. Behavior patterns and communication in feral horses. Z. Tierpsychol., 41, 337-371.

Fischhoff, I.R., Sundaresan, S.R., Cordingley, J., Larkin, H.M., Sellier, M.-J. and Rubenstein, D.I., 2007. Social relationships and reproductive state influence leadership roles in movements of plains zebra, Equus burchellii. Anim. Behav., 73, 825-831.

Geist, V., 1974. On the Relationship of Social Evolution and Ecology in Ungulates. Amer. Zool., 14, 205-220.

Giraldeau, L.-A., 1997. The ecology of information use. In: J.R., Krebs and N.B., Davies (Eds.), Behavioural ecology : an evolutionary approach. Blackwell Science, Cambridge, Mass.

Goldschmidt-Rothschild, V.B. and Tschanz, B., 1978. Soziale Organisation und Verhalten einer Jungtierherde beim Camargue-Pferd. Z. Tierpsychol., 46, 372-400.

Hare, B., Call, J., Agnetta, B. and Tomasello, M., 2000. Chimpanzees know what conspecifics do and do not see. Anim. Behav., 59, 771-785.

Hare, B., Call, J. and Tomasello, M., 2001. Do chimpanzees know what conspecifics know? Anim. Behav., 61, 139-151.

Heitor, F., do Mar Oom, M. and Vicente, L., 2006a. Social relationships in a herd of Sorraia horses Part I. Correlates of social dominance and contexts of aggression. Behav. Process., 73, 170-177.

Heitor, F., do Mar Oom, M. and Vicente, L., 2006b. Social relationships in a herd of Sorraia horses: Part II. Factors affecting affiliative relationships and sexual behaviours. Behav. Process., 73, 231-239.

Heyes, C., Galef, B.G., 1996. Social learning in animals: the roots of culture. Academic Press, Inc., San Diego, CA. 
Hinde, R.A., 1983. A conceptural framework. In: R.A, Hinde (Ed.), Primate Social Relationships. Sinauer, Sunderland, Massechusetts, pp. 1-7.

Houpt, K.A. and Wolski, T.R., 1980. Stability of equine hierarchies and the prevention of dominance related aggression. Equine Vet J, 12, 15-18.

Houpt, K.A., Law, K. and Martinisi, V., 1978. Dominance hierarchies in domestic horses. Appl. Animal. Ethol., 4, 273-283.

Illius, A.W. and Gordon, I.J., 1987. The Allometry of Food Intake in Grazing Ruminants. J Anim Ecol, 56, 989-999.

Jarman, P.J.., 1974. The social behaviour of antelope in relation to their ecology. Behaviour, 48, 213-267.

King, S.R.B. and Gurnell, J., 2005. Habitat use and spatial dynamics of takhi introduced to Hustai National Park, Mongolia. Biol. Conserva., 124, 277-290.

Krueger, K., 2007. Behaviour of horses in the "round pen technique". Appl. Anim. Behav. Sci., 104, 162170.

Krueger, K. and Flauger, B., 2007. Social learning in horses from a novel perspective. Behav. Process., 76, 37-39.

Krueger, K. and Heinze, J., 2007. Horse sense: social status of horses (Equus caballus) affects their likelihood of copying other horses' behavior. Anim Cogn, in Press.

Laland K.N., 2004. Social learning strategies. Learn Behav, 32, 4-14.

Li, F.-H., Zhong, W.-Q., Wang, Z. and Wang, D.-H., 2007. Rank in a food competition test and humoral immune functions in male Brandt's voles (Lasiopodomys brandtii). Physiol. Behav., 90, 490-495.

Lindberg, A.C., Kelland, A. and Nicol, C.J., 1999. Effects of observational learning on acquisition of an operant response in horses. Appl. Anim. Behav. Sci., 61, 187-199.

Linklater, W.L. and Cameron, E.Z., 2000. Tests for cooperative behaviour between stallions. Anim. Behav., 60, 731-743.

McDonnell, S.M., 2003. The Equid Ethogram: A Practical Field Guide to Horse Behavior. Eclipse Press, Lexington, Kentucky.

McDonnell, S.M. and Haviland, J.C.S., 1995. Agonistic ethogram of the equid bachelor band. Appl. Anim. Behav. Sci., 43, 147-188.

Miyashita, Y., Nakajima, S. and Imada, H., 2000. Differential outcome effect in the horse. J Exp Anal Behav, 74, 245-253.

Moehlman P. D., 2002. Equids : zebras, asses and horses : status survey and conservation action plan. IUCN, Gland, Switzerland.

Nicol, C.J., 2002. Equine learning: progress and suggestions for future research. Appl. Anim. Behav. Sci., 78, 193-208.

Nicol, C.J., 2006. How animals learn from each other. Appl. Anim. Behav. Sci., 100, 58-63.

Poysa, H., 1992. Group Foraging in Patchy Environ- ments: The Importance of Coarse-Level Local Enhancement. Ornis[ Scand[, 23, 159-166.

Pusey, A.E. and Packer, C., 2003. The Ecology of relationships. In: J.R., Krebs, N.B., Davis and (Ed.), Behavioural Ecology. Blackwell Scientific Publication, Oxford, pp. 254-283.

R Development Core Team, 2007. R: A Language and Environment for Statistical Computing. Foundation for Statistical Computing, Vienna.

Salter, R.E. and Hudson, R.J., 1979. Feeding ecology of feral horses in western Alberta. J. Range. Mgmt., 32, 221-225.

Shi, J. and Dunbar, R., 2006. Feeding competition within a feral goat population on the Isle of Rum, NW Scotland. J. Ethol., 24, 117-124.

Shrader, A.M., Kerley, G.I.H., Kotler, B.P. and Brown, J.S., 2007. Social information, social feding, and competition in group-living goats (Capra hircus). Behav. Ecol., 18, 103-107.

Thouless, C.R., 1990. Feeding competition between grazing red deer hinds. Animal Behaviour, 40, 105111.

Tyler, S.J., 1972. The behaviour and social organisation of the new Forest ponies. Anim Behav Monogr, 5, 85-196.

Valone, T.J. and Templeton, J.J., 2002. Public information for the assessment of quality: a widespread social phenomenon. Philosophical Transactions of the Royal Society B: Biological Sciences, 357, 15491557.

Valone, T.J., 1989. Group foraging, public information, and patch estimation. Oikos, 56, 357-363.

Waring, G.H., 2003. Horse behavior. Noyes Publishing, Norwich, N.Y.

Weckerly, F.W., 1999. Social bonding and aggression in female Roosevelt elk. Can J Zool, 77, 1379-1384. Wittemyer, G. and Getz, W.M., 2007. Hierarchical dominance structure and social organization in African elephants, Loxodonta africana. Anim. Behav., 73, 671-681.

Wittenberger, J.F., 1981. Animal Social Behavior. Duxbury Press, Boston. 